Int. J. Electrochem. Sci., 11 (2016) 10185 - 10198

\title{
Corrosion Studies of Carbon Steel Immersed in NACE Brine by Weight Loss, EIS and XRD Techniques
}

\author{
Román Cabrera-Sierra ${ }^{1,2 *}$, L. J. Cosmes-López ${ }^{1}$, Homero Castaneda-López ${ }^{2,3}$, Jesús Torres Calderón ${ }^{1}$, \\ J. M. Hallen López ${ }^{4}$ \\ ${ }^{1}$ Instituto Politécnico Nacional, Escuela Superior de Ingeniería Química e Industrias Extractivas. \\ Departamento de Ingeniería Química Industrial, Edif. 7, UPALM Zacatenco, México, D.F. C.P. 07738. \\ ${ }^{2}$ Chemical and Biomolecular Engineering Department, The University of Akron, Akron, Ohio 4325, \\ USA. \\ ${ }^{3}$ National Corrosion Center, Material Science and Engineering Department, Texas A\&M University. \\ College Station, TX 77843. \\ ${ }^{4}$ Instituto Politécnico Nacional, Escuela Superior de Ingeniería Química e Industrias Extractivas. \\ Departamento de Metalurgia y Materiales, UPALM Zacatenco, México, D.F. C.P. 07738. \\ *E-mail: romaipn@gmail.com
}

doi: $10.20964 / 2016.12 .32$

Received: 28 June 2016 / Accepted: 22 September 2016 / Published: 10 November 2016

Weight loss and corrosion rate measurements were determined by the immersion of the carbon steel for 24 hours in NACE brine; varying the rotation speed (200, 1000 and $2000 \mathrm{rpm})$ and the temperature (35, 50 and $65{ }^{\circ} \mathrm{C}$ ). At this immersion time, the steel interface was further characterized by Electrochemical Impedance Spectroscopy technique (EIS), using the rotating cylinder electrode configuration. It was observed an increase in the oxidation of the steel by influence of the rotation mainly at temperatures of 50 and $65{ }^{\circ} \mathrm{C}$; the corrosion rates increase from 25.99 to 110.52 and 45.2 to 135.27 mpy, respectively. This active oxidation is evident in the EIS characterization recording a shrinkage of the complex plots as the rotation and temperature were enhanced. According to the EIS analysis the electrochemical responses are governed by the oxygen diffusion process through the corrosion products under the influence of the electrode rotation. Using XRD analysis, the iron compounds formed by oxidation - precipitation after the immersion are mainly composed by magnetite $\left(\mathrm{Fe}_{3} \mathrm{O}_{4}\right)$ and feroxyhyte $(\delta$-FeOOH$)$, respectively; being the feroxyhyte partially removed by the rotation favoring the active dissolution of the steel.

Keywords: Corrosion, EIS, brine, RCE

$\underline{\text { FULL TEXT }}$ 
(C) 2016 The Authors. Published by ESG (www.electrochemsci.org). This article is an open access article distributed under the terms and conditions of the Creative Commons Attribution license (http://creativecommons.org/licenses/by/4.0/). 